\title{
Research on fracture behavior of a Cr coating/ laser pre-quenched steel substrate system under thermal fatigue loading
}

\author{
Ban-Quan Yang, a, Guang-Nan Chen², Xue-Jun Chen ${ }^{3}$, Wei-Hai Sun ${ }^{1}$, \\ Hong-Qian Chen ${ }^{1}$, Jing-Wen Pan $^{1}$ and Ying Chen ${ }^{1}$
}

${ }^{1}$ Division of Engineering Mechanics, Department of Mechanical Engineering, Academy of Armored Force Engineering, No. 21, Du-Jia-Kan, Chang-Xin-Dian, Beijing 100072, P. R. China

${ }^{2}$ Laboratory of surface modification, Institute of mechanics, Chinese Academy of Sciences, No. 15 Bei-si-huan-xi Road, Beijing 100190, P. R. China

${ }^{3}$ School of Applied Sciences, University of Science and Technology Beijing, No. 30 Xue-Yuan Road, Beijing 100083, P. R. China

ayangbq1022@sina.com

Keywords: Crack density; Cr coating/ laser pre-quenched steel substrate system; Thermal fatigue loading.

\begin{abstract}
The facture behavior of a chromium (Cr) coating/ laser pre-quenched steel substrate system was investigated in this work. The results presented in this work show the crack density of the $\mathrm{Cr}$ coating on the laser pre-quenched steel substrate increases with the increase of the thermal fatigue times, and the failure process and modes of the $\mathrm{Cr}$ coating / laser pre-quenched steel substrate are the same as those presented in our previous work. However, the crack density of $\mathrm{Cr}$ coating on the pre-quenched substrate surface was much lower than that of the $\mathrm{Cr}$ coating on the original substrate surface under the same thermal fatigue loading. This indicates the $\mathrm{Cr}$ coating on the pre-quenched steel substrate has superior mechanical properties than that on the original steel substrate.
\end{abstract}

\section{Introduction}

Cr coatings have been widely used on engineering parts and composites such as piston rings, work rolls and aircraft landing gear etc. due to their high hardness, excellent wear and corrosion resistance, high melting point and low coefficient of friction [1]. However, under the severe service conditions such as thermal fatigue loading, gas erosion and severe stressing, cracking is usually caused at the coating or the substrate/chromium interface, which will result in the spallation of the chromium coatings from the substrate $[2,3]$. The spallation of the coating from the substrate means the failure of the coating-substrate system to a certain extent. In these severe service conditions, the thermal fatigue loading is often considered to be the dominating factor that causes the engineering parts or composites failure, and the fracture behaviors and failure mechanisms of coatings under this loading have been the subject of considerable research $[4,5]$. With more and more severe operating conditions, the single traditional chromium plating cannot meet the practical requests. In order to satisfy the practical requests, a novel technology of laser pre-quenching of steel substrate surface prior to plating the $\mathrm{Cr}$ coating has been presented [6-8]. However, the failure process and modes of this material system and the effect of this technology on the mechanical properties of the coating under thermal fatigue loading are still lacking. The mechanical properties of a coating on its substrate are considered to be crucial intrinsic parameters determining performance and reliability of coating-substrate system. In this work, the fracture behaviors and mechanical properties under thermal fatigue loading of a $\mathrm{Cr}$ coating/laser pre-quenched steel substrate system are investigated.

\section{Experimental procedure and results}

The substrate material was as-quenched and tempered 30CrNi2MoV (AISI 3034) steel (main chemical ingredients: $0.28 \mathrm{C}, 0.7 \mathrm{Cr}, 2.27 \mathrm{Ni}, 0.20 \mathrm{Mo}, 0.21 \mathrm{~V}$, all in wt. \%). The steel plate 
$99 \mathrm{~mm} \times 16.5 \mathrm{~mm} \times 5 \mathrm{~mm}$ was quenched using a continuous $\mathrm{CO}_{2}$ laser with beam power $600 \mathrm{~W}$, beam diameter $5 \mathrm{~mm}$ and beam scanning velocity $10 \mathrm{~mm} / \mathrm{s}$. The beam interval between two laser tracks is large enough so that the interaction between the neighboring tracks can be ignored. Their laser-quenched surfaces were mechanically ground and polished. The $\mathrm{Cr}$ coatings composed of low-contraction (LC) and high-contraction (HC) $\mathrm{Cr}$ were prepared by the commercial electroplating processing of the practical chromium-coated parts. The LC-Cr layer about $20 \mu \mathrm{m}$ thick was pre-deposited as an interlayer with the commercial plating bath of chromic acid $\left(250 \mathrm{gl}^{-1}\right)$ and sulfuric acid $\left(2.5 \mathrm{gl}^{-1}\right)$, at a temperature of $85{ }^{\circ} \mathrm{C}$ and a current density of $60 \mathrm{~A} / \mathrm{dm}^{2}$. The $\mathrm{HC}-\mathrm{Cr}$ plate approximately $110 \mu \mathrm{m}$ thick was deposited at a lower bath temperature and a lower current density.

In this work, the number of specimens of the Cr coating /laser pre-quenched steel substrate is 8 . The representative optical microscope of the cross section of the specimen is shown in Fig.1.

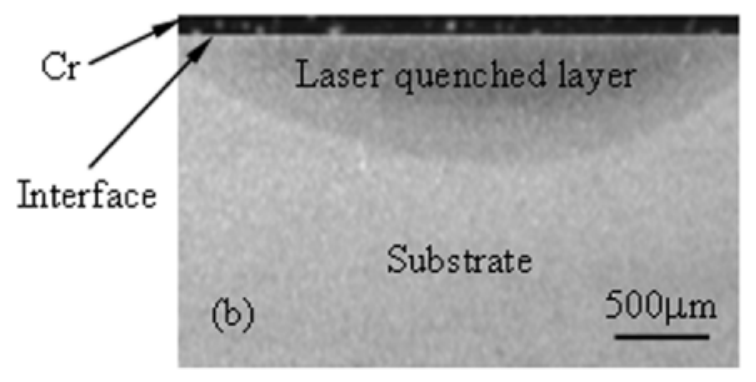

Fig. 1. The optical photo of the cross section of the specimen

In this experiment, all the specimens were heated simultaneously in an electromagnetic oven at $650 \mathrm{C}^{0}$ with a heating rate of approximately $200 \mathrm{C}^{0} / \mathrm{min}$. After the temperature of the specimens remained $650 \mathrm{C}^{0}$, they were quickly removed from the induction oven, and quenched with water at temperature of $12 \mathrm{C}^{0}$. The heated and quenched process repeated. After the thermal cycle times reached the designed number, specimens were taken out. Then, they were mechanically ground and polished. The representative optical microscopes of the cross section of the specimens after 100, 200, 400, 650, 800, 1300 cycles are shown in Figs.2 (A), (B), (C), (D), (E), (F), respectively.

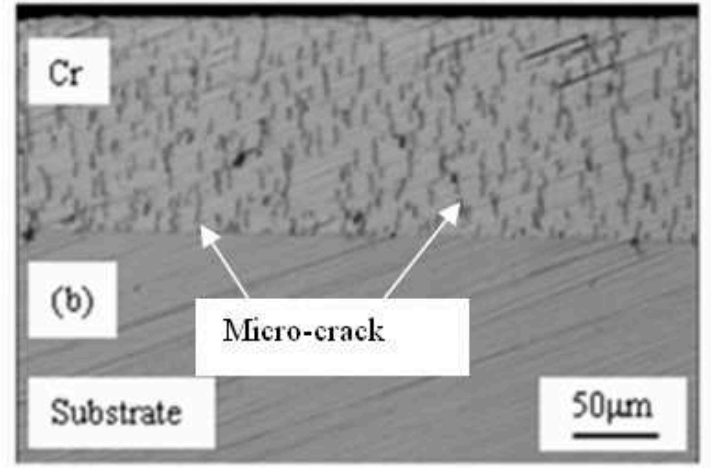

(A) 100 cycles

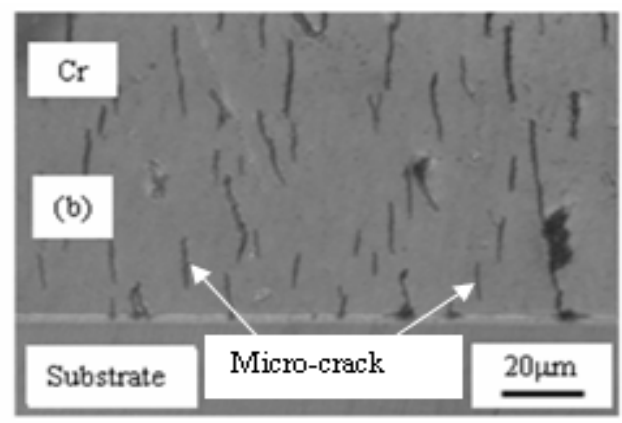

(C) 400 cycles

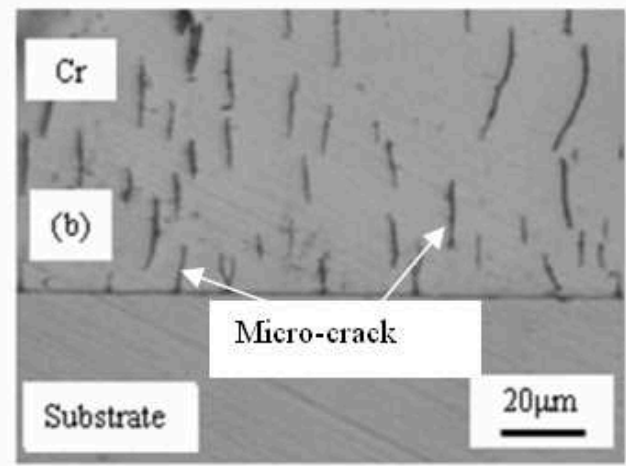

(B) 200 cycles

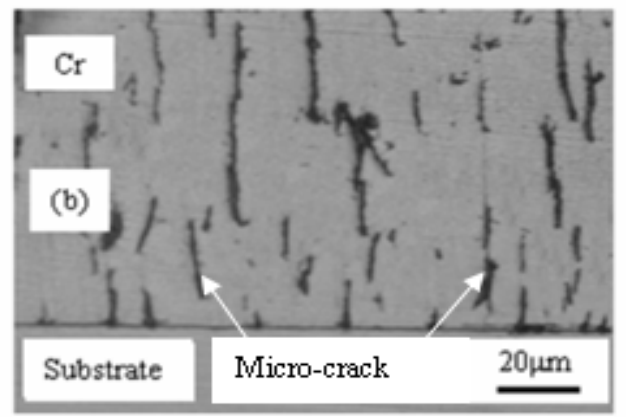

(D) 650 cycles 


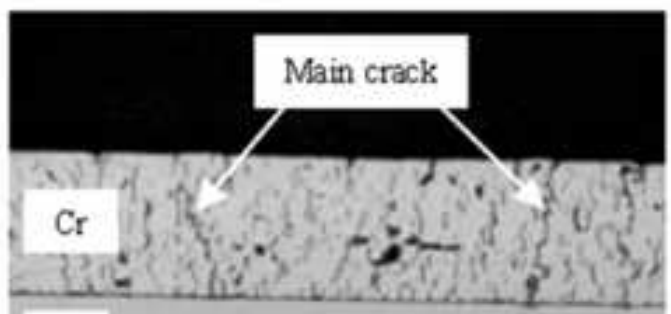

(b)

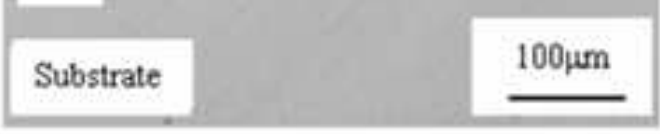

(E) 800 cycles

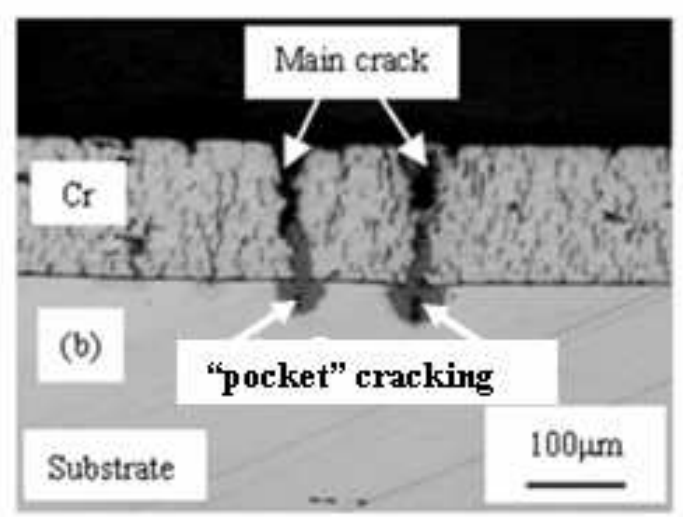

(F) 1300 cycles

Fig. 2. The representative optical microscopes of the cross section of the specimens after 100, 200, $400,650,800,1300$ cycles shown in (A), (B), (C), (D), (E), (F), respectively.

\section{Characterization of the crack density}

A more suitable parameter to characterize the crack density of the coating on the substrate was presented in our previous work [9]. The expression is

$$
\varepsilon_{C}=\frac{\sum_{i=1}^{N} L_{C i} \times B_{C i}}{A}
$$

Where $\varepsilon_{C}$ is the crack density of the coating, $A$ is the area of the coating, $N$ is the number of the cracks of the coating, $L_{C i}$ is the crack length, and $B_{C i}$ is the average crack width. All the parameters can be measured using the optical microscope. The average crack density corresponding to the thermal fatigue times of the $\mathrm{Cr}$ coating on the laser pre-quenched steel substrate is also calculated from Eq. (1). In our previous work [9], the facture behavior and the crack density of a Cr coating on the original steel substrate under the same fatigue thermal loading was investigated, and the variation law of the crack density vs. the thermal fatigue times is shown in Fig.3

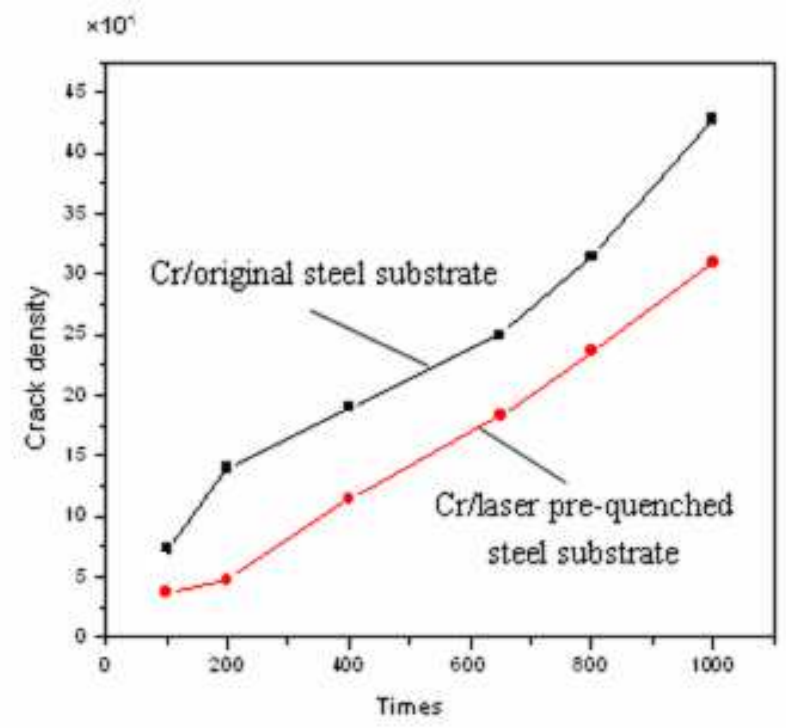

Fig.3. The variation of the crack density of the coatings vs. the thermal fatigue times 


\section{Discussions and results}

From Figs.2 (A-E), it can be seen that the failure process and modes of the coating can be described as follows: Firstly, the micro-cracks of the coatings grew and interconnected as the thermal fatigue time increased. Secondly, the "pocket" cracking at the coating and the substrate interface occurred, and the main cracks of the coating formed. As the thermal fatigue time increases, finally, the spallation or (and) collapse of the coating occurred. The failure process and modes of the $\mathrm{Cr}$ coating / laser pre-quenched steel substrate are the same as those presented in our previous work [9]. From Fig.3, it can be seen that the crack density of $\mathrm{Cr}$ coating on the original steel substrate increases with increasing the thermal fatigue times. However, the crack density of $\mathrm{Cr}$ coating on the pre-quenched substrate surface was much lower than that of the $\mathrm{Cr}$ coating on the original substrate surface under the same thermal fatigue loading. This indicates the $\mathrm{Cr}$ coating on the pre-quenched steel substrate has superior mechanical properties than that on the original steel substrate.

\section{Acknowledgements}

The authors gratefully acknowledge the financial support of the Innovative Science Foundation of Academy of Armored Force Engineering (Grant No. 2013CJ11), the financial support of the National Natural Science Foundation of China (Grant No. 51171026, 51075398, 51102283).

\section{References}

[1] K.M.Yin and C.M.Wang: Surf. Coat. Technol. Vol.114(1999), p.218.

[2] J.Simão ang D.K. Aspinwall: J. Mater. Process. Technol. Vol. 92-93(1999), p. 218.

[3] L.Fedrizzi, S.Rossi , F.Bellei and F.Deflorian: Wear, Vol.253 (2002), p.1173.

[4] B.Lawton: Wear, Vol. 251(2001), p. 827.

[5] S.Sopok, C.Richard and S.Dunn: Wear, Vol. 258 (2005), p. 659.

[6] H.X. Li, G.N. Chen, G.X. Zhang, K. Zhang and G.X. Luo: Surf. Coat. Technol. Vol.201 (2006), p. 902.

[7] B.Q. Yang, K. Zhang, G.N. Chen, G.X. Luo and J.H. Xiao: Acta. Mater. Vol. 55(2007), p. 4349.

[8] B.Q. Yang, K. Zhang, G.N. Chen, G.X. Luo and J.H. Xiao: Surf. Coat. Technol. Vol. 201(2006), p. 2208.

[9] B.Q. Yang, G.N. Chen, J. Du, X. J Chen, W.H Sun, H. Q Chen, J.W. Pan and Y. Chen: Appl. Mech. Mater. Vol. 470 (2014), p. 146. 
Vehicle, Mechatronics and Information Technologies II

10.4028/www.scientific.net/AMM.543-547

\section{Research on Fracture Behavior of a Cr Coating/Laser Pre-Quenched Steel Substrate System under Thermal Fatigue Loading}

10.4028/www.scientific.net/AMM.543-547.3772

\section{DOI References}

[1] K.M. Yin and C.M. Wang: Surf. Coat. Technol. Vol. 114(1999), p.218.

http://dx.doi.org/10.1016/S0257-8972(99)00046-8

[3] L. Fedrizzi, S. Rossi , F. Bellei and F. Deflorian: Wear, Vol. 253 (2002), p.1173.

http://dx.doi.org/10.1016/S0043-1648(02)00254-5

[4] B. Lawton: Wear, Vol. 251(2001), p.827.

http://dx.doi.org/10.1016/S0043-1648(01)00738-4

[5] S. Sopok, C. Richard and S. Dunn: Wear, Vol. 258 (2005), p.659.

http://dx.doi.org/10.1016/j.wear.2004.09.031

[6] H.X. Li, G.N. Chen, G.X. Zhang, K. Zhang and G.X. Luo: Surf. Coat. Technol. Vol. 201 (2006), p.902. http://dx.doi.org/10.1016/j.surfcoat.2006.01.011

[7] B.Q. Yang, K. Zhang, G.N. Chen, G.X. Luo and J.H. Xiao: Acta. Mater. Vol. 55(2007), p.4349.

http://dx.doi.org/10.1016/j.actamat.2007.04.002

[8] B.Q. Yang, K. Zhang, G.N. Chen, G.X. Luo and J.H. Xiao: Surf. Coat. Technol. Vol. 201(2006), p.2208. http://dx.doi.org/10.1016/j.surfcoat.2006.03.030

[9] B.Q. Yang, G.N. Chen, J. Du, X. J Chen, W. H Sun, H. Q Chen, J.W. Pan and Y. Chen: Appl. Mech. Mater. Vol. 470 (2014), p.146.

http://dx.doi.org/10.4028/www.scientific.net/AMM.470.146 